\title{
The Contact Performance Analysis of Disconnecting Switch's Fixed Contact
}

\author{
Bufan LI, Na LU*, Yufeng HE \\ School of Automation Beijing University \\ of Posts and Telecommunications, \\ Beijing, China \\ E-mail: lbf911@ 126.com; *E-mail: nalu@bupt.edu.cn; E-mail: 1512623259@qq.com \\ $+*$ Corresponding author
}

\begin{abstract}
In order to optimize and improve the GW6 disconnecting switch's fixed contact existing structure, this paper, according to its conditions, sets up the analysis model by SolidWorks. In the integrated AWE exploiting environment, this paper does finite element analysis for its contact performance and temperature rising. To acquire the contact area and contact condition, it compares with four structures: original structure (no groove), the structure which has groove, the structure which has groove but not matching the ACSR, the structure with the cylinder ACSR. As a result, via changing the ACSR to the cylinder structure, the switch increases the area of contact surface, improves the contact condition, reduces the temperature rising. It solves the problem of overheat of conductive circuit, which makes the operation of the electric power system safe and reliable.
\end{abstract}

Keyword-disconnecting switches; finite element analysis; ANSYS; structure; temperature rising

\section{INTRODUCTION}

High voltage disconnecting switches' main function is making the charged and the uncharged parts separate in the high-voltage distribution equipment to guarantee safely repair. In power transmission and transformation system, disconnecting switches are important components, which is the largest quantity and widely used. Their reasonability of design and the quality of management and maintenance have the direct relation to the safe operation of the electric power system. With the increase of power construction investment, the growth rate of maximum load is larger than power usage in our power net. Disconnecting switches become the weak point in electric power circuit, whose capability directly affects the net's reliable operation. Although enterprises have taken many proper precautionary and maintenance measures, disconnecting switches also cannot run effectively and permanently. While the new inexpensive structures' performance becomes closer to the standard ultimate, if disconnecting switch has unreasonable design or not maintains in time, there will be contact failure. For instance, Fig. 1 is the disconnecting switch's fixed contact infrared thermometry picture on high-voltage transmission lines in WenShan substation on January 9, 2013. This picture shows that the \#-shaped II loop 50311 disconnecting switch's B and $\mathrm{C}$ phase fixed contacts have unusual temperature (A phase :21 B phase : 163 C phase : 104)
In actual operation, disconnecting switch is under the effect of harsh environment and complex climatic condition. With the increase of the operation time, switch often occurs overheat in conducting circuit. When it becomes overheat, the load which on switch should be limited. Sometimes it should cut off power urgently. These cases affect the safe operation of power net and reliability of power supply. The main reason of these faults is not only related to the environment but also related to its own structure [1]. According to the condition of disconnecting switch's fixed contact, this paper builds the model in ANSYS workbench. Via analyzing the performance of different fix contact structure and the thermal effects, it can optimize structure, have better performance, reduce the loop's temperature rising or overheat and make the power system operation safe.

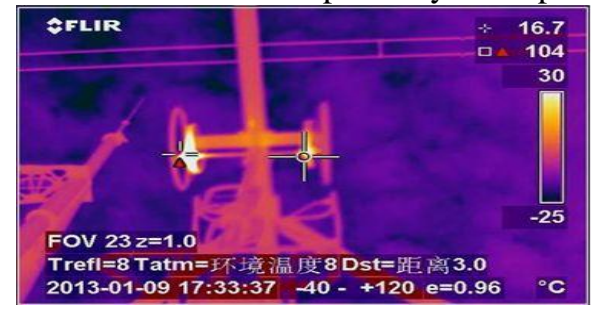

(a) B phase fix contact

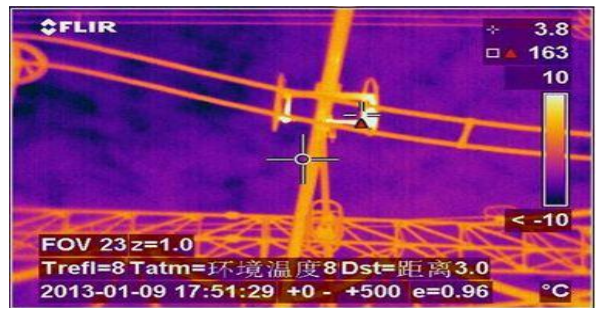

(b) C phase fix contact

Figure 1. Fixed contact infrared thermometry picture

\section{ANALYSis OF DisconNeCTING SWITCH'S FIXED CONTACT}

This paper uses the clamp of GW6 type disconnecting switch's fixed contact. Because of the ACSR twisted by multi-strand, the ACSR in clamp and the splint is the linear and facial contact. This structure has its weakness, which makes the disconnecting switch overheat or breakdown, especially in the tough and complex condition [2]. 
This paper makes some structural improvements for the GW6 type disconnecting switch's fixed contact: 1) Let the splint have grooves. 2) Let the ACSR become cylinder. These make the ACSR and the splint the linear and facial contact. In order to explain the effect of structure on the contact area contact state and temperature rising, this article conducts static and electro-thermal analysis.

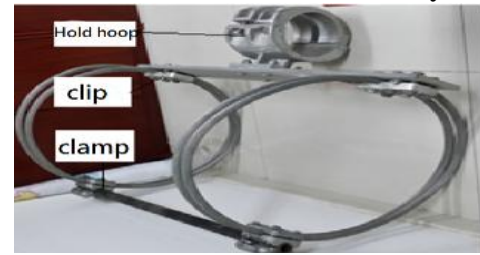

Figure 2. Disconnecting switch's fixed contact

\section{A. Linear Structural Static Analysis.}

In order to acquire the contact area and contact condition, this article compares with four structures: original structure (no groove), the structure which has groove, the structure which has groove but not matching the ACSR, the structure with the cylinder ACSR.

\section{1) Model}

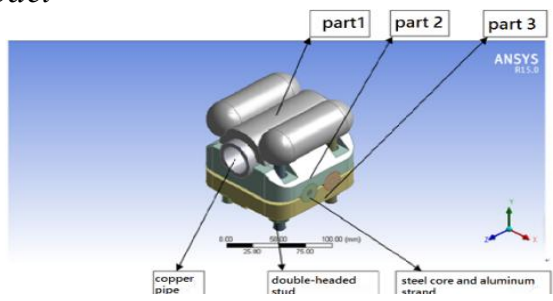

Figure 3. The whole model

TABLE I. Parts, Material ANd Performance

\begin{tabular}{|c|c|c|c|c|}
\hline Name & Material & $\begin{array}{l}\text { Young's } \\
\text { modulus }\end{array}$ & $\begin{array}{l}\text { Poisson's } \\
\text { ratio }\end{array}$ & $\begin{array}{l}\text { Shear } \\
\text { modulus }\end{array}$ \\
\hline Part 1 & $\begin{array}{l}\text { Aluminum } \\
\text { Alloy }\end{array}$ & $\begin{array}{l}\text { 7.1E+10 } \\
\mathrm{Pa}\end{array}$ & 0.33 & $2.6692 \mathrm{E}+10 \mathrm{~Pa}$ \\
\hline Part 2 & $\begin{array}{l}\text { Aluminum } \\
\text { Alloy }\end{array}$ & $\begin{array}{l}7.1 \mathrm{E}+10 \\
\mathrm{~Pa}\end{array}$ & 0.33 & $2.6692 \mathrm{E}+10 \mathrm{~Pa}$ \\
\hline Part 3 & $\begin{array}{l}\text { Aluminum } \\
\text { Alloy }\end{array}$ & $\begin{array}{l}7.1 \mathrm{E}+10 \\
\mathrm{~Pa}\end{array}$ & 0.33 & $2.6692 \mathrm{E}+10 \mathrm{~Pa}$ \\
\hline $\begin{array}{l}\text { Double-headed } \\
\text { stud }\end{array}$ & $\begin{array}{l}\text { stainless } \\
\text { steel }\end{array}$ & $\begin{array}{l}1.9 \mathrm{E}+11 \\
\mathrm{~Pa}\end{array}$ & 0.31 & $7.3664 \mathrm{E}+10 \mathrm{~Pa}$ \\
\hline Steel core & $\begin{array}{l}\text { stainless } \\
\text { steel }\end{array}$ & $\begin{array}{l}1.93 \mathrm{E}+11 \\
\mathrm{~Pa}\end{array}$ & 0.31 & $7.3664 \mathrm{E}+10 \mathrm{~Pa}$ \\
\hline $\begin{array}{l}\text { Aluminum } \\
\text { strand }\end{array}$ & $\begin{array}{l}\text { Aluminum } \\
\text { Alloy }\end{array}$ & $\begin{array}{l}7.1 \mathrm{E}+10 \\
\mathrm{~Pa}\end{array}$ & 0.33 & $2.6692 \mathrm{E}+10 \mathrm{~Pa}$ \\
\hline
\end{tabular}

Since the model has two symmetry planes, this article uses the quarter of the whole model as the target. The results shown in Fig. 4.

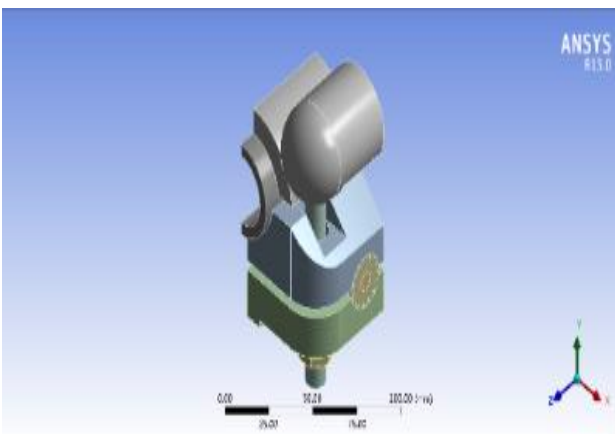

(a) structure 1, original structure (no groove)

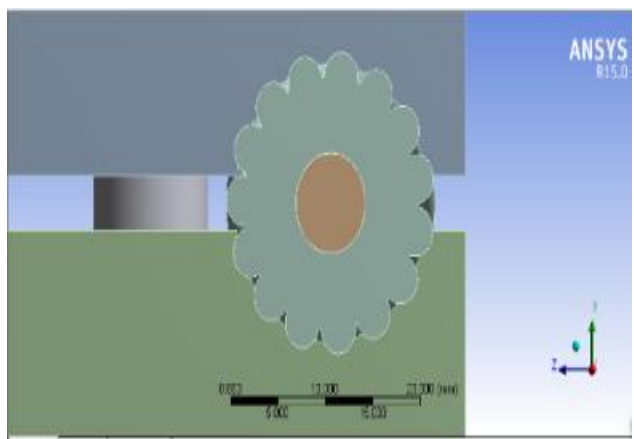

(b) structure 2, the structure which has groove

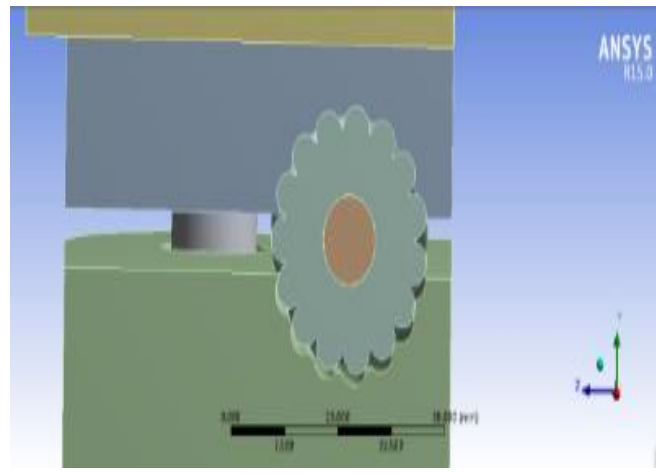

(c) structure 3, the structure which has groove but not matching the ACSR

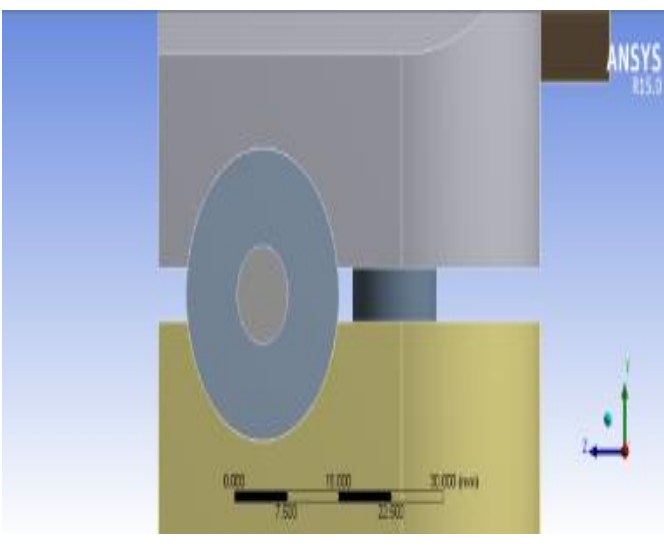

(d) structure 4, the structure with the cylinder ACSR

Figure 4. Four different quarter of model 


\section{2) The simulation result}

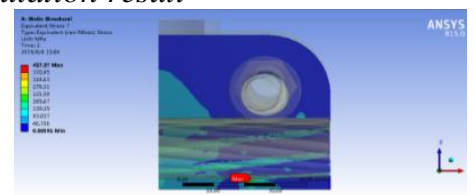

(a)

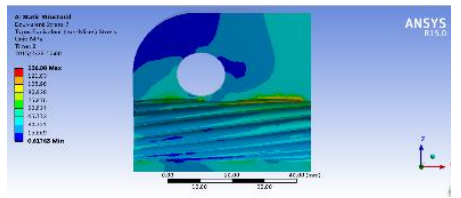

(b)

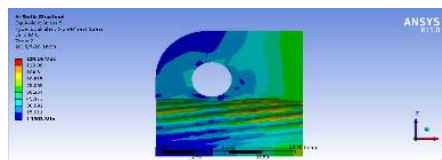

(c)

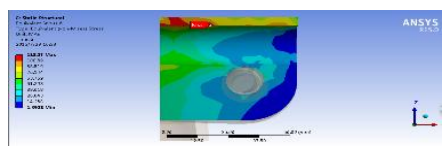

(d)

Figure 5. Surface stress of part 2 and ACSR

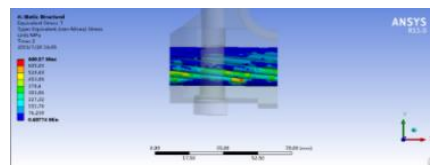

(a)

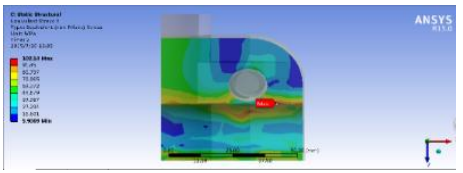

(b)

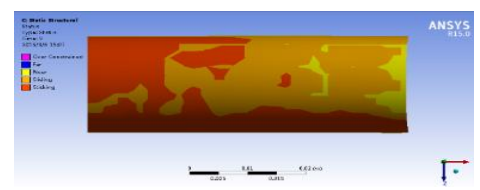

(c)

Figure 6. Other structures surface stress simulation

The two figures are the four times simulation analysis results of four structures. Fig.5 is structures surface stress of part 2 and ACSR. Fig.6 (a) is surface stress of part 3 result of structure which has groove. Fig.6 (b) is surface stress of ACSR result of the structure which has groove but not matching the ACSR. Fig.6 (c) is interface contact condition (clamp) result of the structure with the cylinder ACSR, which pink area is fixed contact. Orange area is sliding contact.
TABLE II. THE MAXIMUM StRESS :/MPA

\begin{tabular}{|l|l|l|l|l|}
\hline Name & Struc1 & Struc2 & Struc3 & Struc4 \\
\hline $\begin{array}{l}\text { Surface stress of part 2 } \\
\text { and ACSR }\end{array}$ & 417.2 & 136.1 & 134.2 & 113.3 \\
\hline $\begin{array}{l}\text { Surface stress of part 3 } \\
\text { and ACSR }\end{array}$ & 478.5 & 238.4 & 633.3 & 102.1 \\
\hline Surface stress of ACSR & 388.7 & 228.7 & 680.6 & 73.0 \\
\hline
\end{tabular}

\section{3) Conclusion}

The structure with the cylinder ACSR, in the same condition, has larger contact area, better contact performance and smaller maximum stress. The structure which has groove also has larger contact area, better contact performance [3]. The surface stress will exceed the fatigue limitation (270-280MPa) if they don't have good matching. The original structure has smaller contact area, worse contact performance, and higher surface stress.

\section{B. Electro-thermal Simulation Analyses}

In order to acquire the effect of structure and temperature rising, the article does the electro-thermal simulation analyses of the disconnecting switch's fixed contact.

1) Model

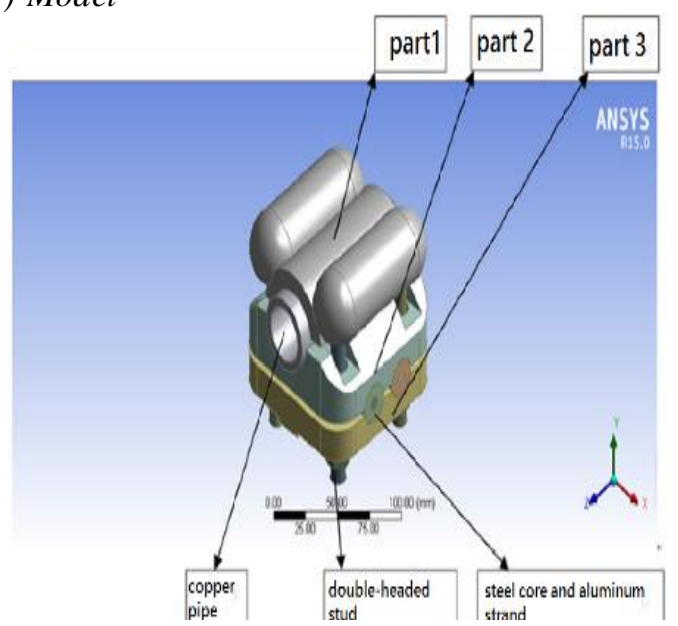

Figure 7. The whole model

TABLE III. THE MATERIAL CHARACTERISTICS

\begin{tabular}{|c|c|c|c|}
\hline Name & Material & $\lambda / \mathbf{W m}^{-1} \mathbf{C}^{-}$ & CTE $/ C^{-1}$ \\
\hline Part1 & Aluminum Alloy & 144 & $2.3 \mathrm{E}-05$ \\
\hline Part2 & Aluminum Alloy & 144 & $2.3 \mathrm{E}-05$ \\
\hline Part3 & Aluminum Alloy & 144 & 2.3E-05 \\
\hline Aluminum strand & Aluminum Alloy & 144 & $2.3 \mathrm{E}-05$ \\
\hline Copper pipe & Copper Alloy & 401 & $1.8 \mathrm{E}-05$ \\
\hline Double-headed stud & stainless steel & 15.1 & $1.7 \mathrm{E}-05$ \\
\hline Steel core & stainless steel & 15.1 & $1.7 \mathrm{E}-05$ \\
\hline
\end{tabular}




\section{2) The simulation result}

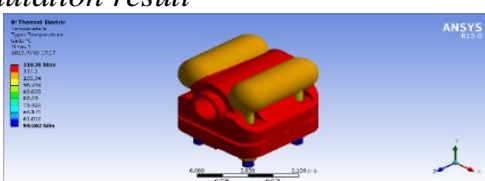

(a)

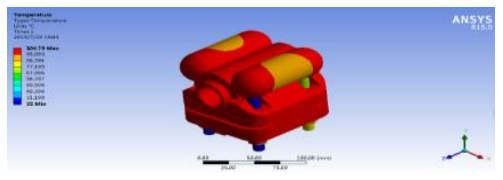

(b)

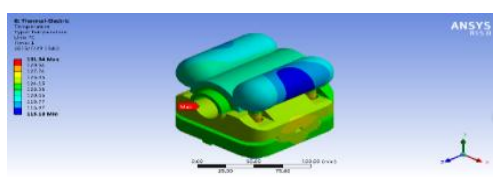

(c)

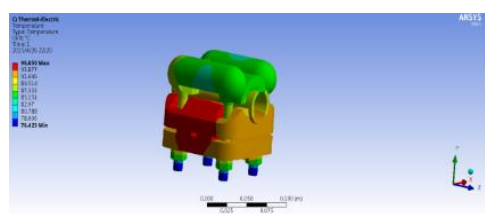

(d)

Figure 8. Overall temperature

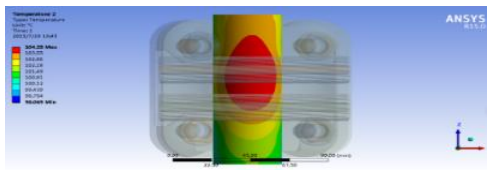

(a)

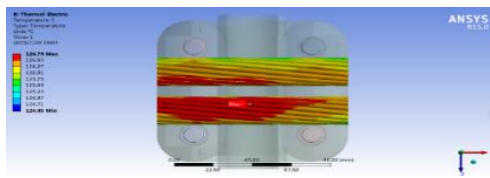

(b)

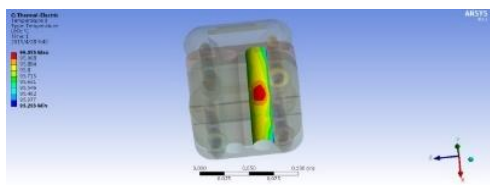

(c)

Figure 9. Result of simulation
This figure is the four times simulation analysis results of four structures. Fig. 8 is original structure's Overall temperature. Fig.9 (a) is copper pipe interface temperature result of structure which has groove. Fig.9 (b) and (c) is Aluminum strand interface result of the structure which has groove but not matching the ACSR.

TABLE IV. The MAXIMUM TeMPeRATURE $/{ }^{\circ} \mathrm{C}$

\begin{tabular}{|l|l|l|l|l|}
\hline Name & Struc1 & Struc2 & Struc3 & Struc4 \\
\hline Overall & 118.25 & 104.79 & 131.34 & 96.059 \\
\hline Copper pipe & 117.8 & 104.23 & 126.52 & 95.877 \\
\hline Aluminum strand & 118.25 & 104.79 & 126.79 & 96.053 \\
\hline
\end{tabular}

\section{3) Conclusion}

By contrasting the four groups of data, in the same contact resistance condition, it can be found that the structure with the cylinder ACSR has the lower temperature, which has $22.19^{\circ} \mathrm{C}$ drops compared with the original structure. The structure which has groove also has the lower temperature. But it will have considerable temperature rising if they are not good matching. The original structure with no groove has smaller contact area, worse contact condition and considerable temperature rising [4]

\section{CONCLUSION}

This paper analyzes the contact performance and temperature rising of disconnecting switch's fixed contact by finite element method to optimize the original structure. Via changing the ACSR to the cylinder structure, the switch increases contact surface, improves the contact condition, reduces the temperature rising [5]. It solves the problem of overheat of conductive circuit, which makes the operation of the electric power system safe and reliable.

\section{REFERENCE}

[1] Tao Fanian,Analysis of present development of Isolator Technology [J],Telecom World,2013.9.

[2] Liu Weifeng, High voltage isolate switch self-contact/contact simulation analysis and structure optimization design [J],High Voltage Apparatus,2011.47(12),6-10

[3] Wu Tao,Yu Haitao,550 kV Analysis of Thermal Stability of high voltage isolator switch [J],High Voltage Apparatus, 2013.49(9),134-140

[4] Luo Guoping,Fault Analysis and Simulation of electrical connector [D],Beijing:BUPT,2000

[5] Ling Guilong,ANSYS workbench 15.0 from entry to master [M],Beijing:Tsinghua University press,2014 